\title{
DEVOLUCIONES EN CALIENTE A LA LUZ DE LA DOCTRINA DE LA CONDUCTA CULPABLE: EL ASUNTO N.D. Y N.T. CONTRA ESPAÑA ANTE EL TEDH
}

\author{
MARTA SOSA NAVARRO' \\ martasosanavarro@gmail.com
}

Cómo citar/Citation

Sosa Navarro, M. (2020).

Devoluciones en caliente a la luz de la doctrina de la conducta culpable: el asunto N.D. y N.T. contra España ante el TEDH. Revista de Derecho Comunitario Europeo, 67, 1039-1061. doi: https://doi.org/10.18042/cepc/rdce.67.08

\section{Resumen}

Este comentario analiza los argumentos jurídicos desarrollados por la Gran Sala del TEDH en el asunto N.D. y N.T. contra España. A través de un examen de la jurisprudencia del propio Tribunal y de los análisis doctrinales más recientes, el presente comentario lleva a cabo un estudio detallado de los fundamentos jurídicos de una sentencia sin precedentes. El pronunciamiento rechaza que la protección del art. 4 del Protocolo 4 del CEDH, que prohíbe las expulsiones colectivas, sea aplicable a los demandantes, entregados por parte de la Guardia Civil a las autoridades marroquíes tras cruzar la frontera a través de la valla de Melilla. Al condicionar la obligación del Estado de respetar el principio de non-refoulement a la conducta de los demandantes y a la existencia de impedimentos objetivos para acceder a las vías legales de entrada,

1 Doctora en Derecho Internacional por la Universidad Carlos III de Madrid y colaboradora externa de la Università Milano-Biccoca. 
el Tribunal se aparta de su propio legado garantista con un tentativo poco logrado de justificar jurídicamente las devoluciones en caliente.

\title{
Palabras clave
}

Expulsión colectiva; artículo 4 Protocolo 4; non-refoulement; jurisdicción extraterritorial; migración; frontera; Melilla; CEDH.

\section{HOT RETURNS IN LIGHT OF THE DOCTRINE OF CULPABLE CONDUCT: THE N.D. AND N.T. AGAINST SPAIN BEFORE THE ECHR}

\begin{abstract}
This commentary analyses the legal arguments issued by the Grand Chamber of the ECHR in the case N.D. and N.T. against Spain. Through a cross-examination of the Court's case-law and recent scholarly writings, this work carries out a detailed study of the legal bases of an unprecedented judgment. The ruling rejects the applicability of the protection of Article 4 of Protocol 4 of the ECHR (which prohibits collective expulsions) to the applicants, handed over by the Civil Guard to the Moroccan authorities after crossing the border through the Melilla fence. By conditioning the State's obligation to respect the principle of non-refoulement to the applicants' conduct and to the existence of objective impediments to enter the country through the existing procedures, the Court departs from its own legacy with an unsuccessful attempt to find a legal justification to hot returns.
\end{abstract}

\section{Keywords}

Collective expulsion; article 4 Protocol 4; non-refoulement; extraterritorial jurisdiction; migration; frontier; Melilla; ECHR.

\section{EXPULSIONS COLLECTIVES A LA LUMIERE DE LA DOCTRINE DE LA CONDUITE COUPABLE: N.D. ET N.T. CONTRE L'ESPAGNE DEVANT LA CEDH}

\section{Résumé}

Ce commentaire analyse les arguments juridiques développés par la Grande Chambre de la CEDH dans l'affaire N.D. et N.T. contre l'Espagne. À travers un examen de la jurisprudence de la Cour et des contributions doctrinales les plus récentes, ce commentaire mène une étude détaillée des bases juridiques d'un arrêt sans précédent. La décision rejette que la protection de l'article $4 \mathrm{du}$ protocole 4 de la $\mathrm{CEDH}$, qui interdit les expulsions collectives, soit applicable aux plaignants, remis 
par la Guardia Civil aux autorités marocaines après avoir franchi la frontière à travers la clôture de Melilla. En conditionnant l'obligation de l'État de respecter le principe de non-refoulement au comportement des plaignants et à l'existence d'obstacles objectifs pour accéder aux voies légales d'entrée, la Cour s'écarte de son propre héritage dans une tentative infructueuse de trouver une justification légale aux refoulements sommaires.

\section{Mots clés}

Expulsion collective; Article 4 Protocole 4; non-refoulement; juridiction extraterritoriale; migration; frontière; Melilla; $\mathrm{CEDH}$. 


\section{SUMARIO}

I. INTRODUCCIÓN. II. LA EXPULSIÓN COLECTIVA. EVOLUCIÓN DE LA JURISPRUDENCIA DEL TEDH. III. EL CAMBIO DE RUMBO DE LA GRAN SALA: UN ANÁLISIS CRÍTICO: 3.1. La conducta «culpable» del demandante como inhibidora de la prohibición de expulsión colectiva. 3.2. El requisito de la ausencia de razones de peso imputables al Estado demandado para hacer uso del procedimiento legal de entrada. 3.3. Otras cuestiones relevantes. IV. CONCLUSIÓN. BIBLIOGRAFíA.

\section{INTRODUCCIÓN}

Los hechos que motivan el presente caso se remontan al 13 de agosto de 2014, fecha en la cual los demandantes, N.D. y N.T., junto con otras setenta personas procedentes de países de África subsahariana, escalaron la valla que separa Melilla de Marruecos, entrando así en suelo español. Según los demandantes, tras ser detenidos inmediatamente por la Guardia Civil, fueron esposados y llevados de vuelta a Marruecos, donde fueron entregados a las autoridades marroquíes. Seis meses después, N.D. y N.T. presentaron una demanda ante el TEDH en la que alegaban que no habían sido objeto de procedimiento de identificación alguno y que no se les había dado la oportunidad de explicar sus circunstancias personales ni de ser asistidos por letrados o intérpretes. Tanto la solicitud de asilo presentada por uno de los demandados como los recursos administrativos presentados por ambos con posterioridad fueron rechazados. El 3 de octubre de 2017, la Sección tercera del TEDH dictó una sentencia en la que sostenía, por unanimidad, que España había incurrido en una violación de la prohibición de expulsión colectiva, recogida en el art. 4 del Protocolo 4 como consecuencia de la ausencia de examen individual de la situación de cada uno de los demandantes, y en una violación del art. 13 del CEDH que tutela el derecho a un recurso efectivo ${ }^{2}$.

Esta sentencia fue celebrada por la doctrina como un reconocimiento de una política pública sistemática de rechazo «ilegal» y de una política migratoria cada vez más restrictiva, que ha intentado "legalizar» las expulsiones en caliente con la adopción de la Ley Orgánica 4/2015 del 30 de marzo de 2015

2 N.D. y N.T c. España, [GC] nos. 8675/15 y 8697/15, párr.167, ECHR 2020. 
de protección de la seguridad ciudadana (Hernández Bologna, 2020: 108). Otros autores la calificaron como un éxito en la protección de los derechos humanos, llegando incluso a bautizarla como «el nuevo Hirsi», en referencia al asunto Hirsi Jamaa y otros contra Italia, que sentó un precedente en la aplicación extraterritorial del Protocolo 4 del CEDH (Pijnenburg, 2017), subrayando como único aspecto crítico el hecho de que al no determinar si el ejercicio de la jurisdicción de España nace de un control de iure (que en este caso viene dado por un control efectivo de las autoridades de este Estado, ya se encuentren estas en el interior del territorio del Estado o en sus fronteras terrestres ${ }^{3}$ ) o únicamente de facto, el Tribunal habría perdido una ocasión única para aclarar esta cuestión (Cobos Romero, 2017: 5).

Esta sentencia fue recurrida por el Gobierno de España, que el 29 de enero de 2018 solicitó que el caso fuera reexaminado por la Gran Sala del Tribunal.

La resolución dictada por el Tribunal de Estrasburgo el 20 de febrero de 2020 como consecuencia de este recurso se encuadra en un complejo entramado normativo. Por un lado, para definir el marco normativo en el que se desarrollan los hechos de los que se ocupa el presente caso, a nivel regional, hay que remitirse a los convenios de Schengen ${ }^{4}$ y de Dublín ${ }^{5}$, así como al Tratado de Maastricht en 1994, en virtud del cual se unifica la política de asilo y de visados al interno de la UE. Además, en el ámbito de los retornos forzosos, juegan un importante papel la Directiva 2008/115/CE o $^{6}$ directiva sobre retorno" y los acuerdos bilaterales o multilaterales en materia migratoria, entre los que deben subrayarse, a efectos del presente comentario, los acuerdos de repatriación, de readmisión y de tránsito ${ }^{7}$, cuya falta de atención a los derechos humanos ha sido denunciada por el Relator Especial sobre

3 N.D. y N.T c. España [Sección III], nos. 8675/15 y 8697/15, párr. 54, ECHR 2017.

4 Acuerdos firmados el 14 de junio de 1985 y cuya principal consecuencia fue la supresión de las fronteras interiores de la Unión Europea.

5 Actualmente está vigente el III, de 2013 (el I es de 1990, mientras que el II es de 2003), y regula el sistema de asilo estableciendo cuál es el Estado miembro responsable del examen de las solicitudes de asilo.

6 Directiva 2008/115/CE del Parlamento Europeo y del Consejo, de 16 de diciembre de 2008, relativa a normas y procedimientos en los Estados miembros para el retorno de los nacionales de terceros países en situación irregular (DO L 348, de 24 de diciembre de 2008).

7 Para un examen detallado de estos acuerdos, así como del sistema regional e internacional de protección de los derechos humanos a la luz de la sentencia de la Sección tercera en el presente caso, dictada el 3 de octubre de 2017, véase Hérnandez Bologna (2020) 
los derechos humanos de los migrantes ${ }^{8}$. En concreto, resulta especialmente pertinente el Acuerdo bilateral entre España y Marruecos ${ }^{9}$, en vigor desde el 2012, sobre todo si, al examinar el presente asunto, recordamos que el propio Tribunal ha afirmado que «lo relevante a tener en cuenta es la práctica efectiva de ese tercer Estado respecto al trato de las personas migrantes readmitidas ${ }^{10}$ \%.

Por otro lado, a nivel doméstico nos enfrentamos a un marco jurídico que ha sido criticado por autores de peso por convertir la normativa migratoria en un derecho de excepción que recorta derechos y garantías procesales (De Lucas, 2015: 105) y que tiene como máximo exponente la LO 4/2015 de Protección de la Seguridad Ciudadana ${ }^{11}$, también llamada «ley mordaza», actualmente pendiente de un recurso de inconstitucionalidad ante el Tribunal Constitucional. Mediante la introducción de la disposición adicional primera que regula el «rechazo en frontera», esta ley recoge un intento de legalización de las devoluciones en caliente respecto al cual ha expresado su preocupación el Alto Comisionado de las Naciones Unidas para los Derechos Humanos ${ }^{12}$. Quede aquí apuntado, para posterior desarrollo, que cualquiera de las formas de admisión, devolución o expulsión recogidas en los instrumentos jurídicos citados (directivas, acuerdos o leyes) debe respetar en todo momento los derechos y garantías recogidos en el $\mathrm{CEDH}$, convirtiendo cualquier acción de hecho en un acto contrario a derecho (Martínez Escamilla, 2016: 89).

Con el fin de completar el contexto en el que se enmarca el presente caso, es preciso aludir al nuevo Pacto sobre Migración y Asilo, publicado el pasado 23 de septiembre por la Comisión Europea ${ }^{13}$. Estamos aquí ante una iniciativa europea que, por un lado, da cuenta de la incapacidad y falta de

8 Consejo de Derechos Humanos de la Asamblea General de Naciones Unidas (2013), Informe del Relator Especial sobre los derechos humanos de los migrantes, François Crépeau. Estudio regional: administración de las fronteras periféricas de la Unión Europea y sus repercusiones sobre los derechos humanos de los migrantes, A/HRC/23/46, párr. 64.

9 Entrada en vigor del Acuerdo entre el Reino de España y el Reino de Marruecos relativo a la circulación de personas, el tránsito y la readmisión de extranjeros entrados ilegalmente, hecho en Madrid el 13 de febrero, del 13 de diciembre de 2012 (BOE, n. ${ }^{\circ} 299$, del 13 diciembre de 2012).

10 Hirsi Jamaa y otros c. Italia [GC], no. 27765/09, párr. 128, ECHR 2012.

11 Ley Orgánica 4/2015, del 30 de marzo, de Protección de la Seguridad Ciudadana (BOE, . $^{\circ} 77$, del 31 marzo de 2015).

12 Asamblea General, Consejo de Derechos Humanos, (2019), Recopilación sobre España. Informe de la Oficina del Alto Comisionado de las Naciones Unidas para los Derechos Humanos, A/HRW/WG.6/35/ESP/.

13 Comisión Europea, (2020), Comunicación de la Comisión relativa al Nuevo Pacto sobre Migración y Asilo, COM (2020) 609 final. 
voluntad para dar respuestas eficaces a los crecientes flujos migratorios que en los últimos cinco años han puesto de manifiesto Estados miembros. Por otro, sin embargo, asume el ambicioso objetivo de aspirar a representar el

marco europeo nuevo y duradero para gestionar la interdependencia entre las políticas y las decisiones de los Estados miembros y para ofrecer una respuesta adecuada a las oportunidades y retos en tiempos normales, en situaciones de presión y en situaciones de crisis: un marco que pueda ofrecer seguridad, claridad y unas condiciones dignas a los hombres, mujeres y niños que llegan a la UE, y que también permita a los europeos confiar en que la migración se gestiona de manera eficaz y humana, en plena consonancia con nuestros valores ${ }^{14}$.

La presente propuesta de reforma de la política migratoria europea, que entre otras cosas incluye un nuevo Reglamento de gestión del asilo y la migración que sustituye al Reglamento de Dublín, ha sido resumida por las voces más críticas como un instrumento que introduce medidas para facilitar el retorno, la externalización de las fronteras y la imposición de cuotas a los Estados miembros ${ }^{15}$. De un examen del documento principal es posible identificar los seis pilares fundamentales en los que se basa esta propuesta: 1) procedimiento acelerado en frontera para establecer el estatuto de manera rápida a la llegada que incluya, para los ciudadanos de terceros países que crucen sin autorización, «un control previo a la entrada, un procedimiento de asilo y, en su caso, un procedimiento de retorno rápido, integrando así procesos que actualmente son independientes» ${ }^{16}$; 2) solidaridad a la carta, o la adopción de un nuevo mecanismo de solidaridad basado en la posibilidad, para los Estados miembros, de elegir entre la acogida voluntaria de solicitantes de asilo en su territorio o el patrocinio de los retornos a los países de origen o tránsito a través de apoyo técnico o económico; 3) mejora del control de la aplicación coherente de las políticas nacionales y de la UE en materia de migración tanto a través de los mecanismos existentes (Schengen y Frontex), como a través de la nueva Agencia de Asilo de la Unión Europea, que asumirá el encargo de supervisar los sistemas de asilo incluidos en el último compromiso con el objetivo de lograr una mayor convergencia; 4) apoyo a la infancia y a las personas vulnerables como objetivo prioritario en el marco de la red europea de tutela y el compromiso de la UE con la erradicación de la trata de seres

14 Ibid.

15 Comisión Española de Ayuda al Refugiado, (2020), «Nuevo Pacto de Migración y Asilo de la UE: cinco claves de una propuesta decepcionante», disponible en: https:// bit.ly/3koLy1T.

16 Comisión Europea, (2020), Comunicación de la Comisión..., op cit., 2.1. 
humanos; 5) refuerzo del control de las fronteras exteriores a través de Frontex, que se convertiría en «el brazo operativo de la política de retorno de la UE», y que debe desarrollarse «sobre la base de la refundición de la Directiva sobre retorno y el apoyo operativo efectivo» ${ }^{17}$, confirmando la imagen de la Europa fortaleza que representa la realidad de unas políticas centradas en externalizar los controles migratorios (Sánchez Legido, 2020: 238); y 6) la modificación de la propuesta de Reglamento Eurodac con la finalidad de crear una base de datos común y actualizada sobre asilo y migración que, entre otras cosas, "contabilice solicitantes individuales (en lugar de solicitudes), para ayudar a aplicar nuevas disposiciones sobre la transferencia de responsabilidades dentro de la UE, con el fin de facilitar la reubicación y garantizar un mejor seguimiento de los retornados» ${ }^{18}$.

La alusión al contenido del Nuevo Pacto Europeo para la Migración y Asilo resulta aún más pertinente si se tiene en cuenta que la sentencia objeto de examen parece alinearse con la filosofía del «retorno rápido» por el que se aboga en esta propuesta, al mismo tiempo apartándose radicalmente de la jurisprudencia consolidada del Tribunal en relación a la obligación de non-refoulement, en un giro restrictivo que ha sido interpretado por un sector de la doctrina como una prueba irrefutable del fin de la concepción dinámica de los derechos humanos en la jurisprudencia del TEDH, tras más de dos décadas de pronunciamientos revolucionarios (Thym, 2020).

\section{LA EXPULSIÓN COLECTIVA. EVOLUCIÓN DE LA JURISPRUDENCIA DEL TEDH}

El art. 4 del Protocolo 4 al CEDH recoge la expresa prohibición de las expulsiones colectivas de extranjeros ${ }^{19}$. El propio TEDH ha precisado que el objetivo mismo de esta disposición es «impedir que los Estados puedan expulsar a determinados extranjeros sin antes examinar sus circunstancias

17 Ibid., 2.5 .

18 Ibid., 2.6. A lo anterior habría que añadir dos aspectos sustanciales del pacto: la adopción de un planteamiento común europeo para las operaciones de búsqueda y salvamento y la intensificación de la colaboración con los socios internacionales de la UE a través del establecimiento de compromisos bilaterales, regionales y multilaterales en materia de readmisiones, devoluciones y lucha contra el tráfico de personas, cuestión que, como hemos visto en el caso del acuerdo UE-Turquía, puede conllevar riesgos de vulneración de derechos humanos.

19 Protocolo 4 al CEDH, art. 4: «Quedan prohibidas las expulsiones colectivas de extranjeros». 
personales y, de esta manera, sin dejarles presentar sus argumentos en contra de la medida adoptada por la autoridad competente» ${ }^{20}$. Estamos aquí ante un concepto que fue definido por primera vez en 1975 por la Comisión en el asunto Henning Becker contra Dinamarca, que tenía por objeto la repatriación de un grupo de doscientos niños vietnamitas por las autoridades danesas ${ }^{21}$ y que, como veremos, ha evolucionado para adaptarse a la realidad del fenómeno migratorio de nuestros tiempos.

Las razones que fundamentan la protección ofrecida por esta disposición pueden conectarse tanto con los riesgos frente a los que protege el art. 3 del Convenio como con la noción de remedio efectivo recogida en el art. 13. Por lo que respecta a la primera disposición, cabe señalar que en el reciente asunto Ilias y Ahmed c. Hungría, el Tribunal estimó que «cuando se expulsaba a los solicitantes de asilo a un tercer país sin examinar el fondo de sus solicitudes de asilo, no se podía saber si las personas objeto de expulsión corrían el riesgo de recibir un trato contrario al artículo 3 en su país de origen o si eran simplemente migrantes económicos, y que solo mediante un procedimiento legal que diera lugar a una resolución se podía llegar a una conclusión sobre esta cuestión y basarse en ella $»^{22}$. No obstante lo anterior, conviene subrayar que, según la jurisprudencia del Tribunal, cuando el demandante no alega un riesgo real de violación de los derechos contenidos en los arts. 2 y 3 del Convenio, la falta de suspensión de una decisión de expulsión no constituye, por sí misma, una violación del art. 13, en relación con el art. 14 del Protocolo $4^{23}$. La obligación de asegurarse sobre el trato que recibirán las personas migrantes que vincula al Estado en cuestión se extiende tanto a los países de origen, de residencia o terceros países (Martínez Escamilla, 2016: 92). De hecho, el principio de no devolución puede ser violado de manera indirecta si el Estado que lleva a cabo la devolución o expulsión no se cerciora de que ese Estado no enviará a la persona a otro país en el que dichos derechos puedan estar en peligro ${ }^{24}$. Algunos autores han interpretado la condicionalidad de la

20 Hirsi Jamaa y otros c. Italia [GC], no. 27765/09, párr. 177, ECHR 2012.

21 Henning Becker c. Dinamarca, no. 7011/75, Consejo de Europa: Comisión Europea de Derechos Humanos, 3 de octubre 1975, D.R.4, p. 252.

22 Ilias y Ahmed c. Hungría [GS], no. 47287/15, párr. 137 ECHR 2019 (traducción de la autora).

23 Khlaifia y otros c. Italia, [GS], no. 16483/12, párr. 281 ECHR 2016.

24 T.I. c. Reino Unido, [decisión de admisibilidad], no. 43844/898, ECHR 2000: «The Court finds that the indirect removal in this case to an intermediary country, which is also a Contracting State, does not affect the responsibility of the United Kingdom to ensure that the applicant is not, as a result of its decision to expel, exposed to treatment contrary to Article 3 of the Convention». 
paralización de la expulsión a la existencia de riesgo real de violación de estos dos artículos exclusivamente como una muestra del rechazo del Tribunal a reconocer las más amplias garantías en el recurso para combatir la expulsión (Castilla, 2017).

La definición misma de la expulsión colectiva requiere abordar el concepto por partes. La doctrina coincide en identificar la ausencia de examen individualizado de las circunstancias personales de las personas migrantes como una característica inherente a la expulsión colectiva (Vacas Fernández, 2017: 232) y vulneradora del derecho internacional (Martínez Escamilla, 2016: 78-79; Solanes Corella, 2017: 206). Sin embargo, tal y como subraya Sánchez Legido, ese examen objetivo representa también un mecanismo para combatir la arbitrariedad, impidiendo que sobre la base de argumentos meramente formales basados en la distinción entre expulsión y no admisión (argumento utilizado por el Gobierno de España en el caso objeto de estudio) se prive de efectividad a la protección ofrecida por el Convenio (Sánchez Legido, 2020: 250). Por un lado, por lo que respecta al alcance de la «expulsión», la jurisprudencia del TEDH ha precisado que el art. 4 del Protocolo 4 es aplicable tanto a la devolución que tiene lugar tras la entrada en territorio nacional (supuesto tradicional ${ }^{25}$ ) como a aquella que se lleva a cabo antes de que la persona haya entrado en el territorio bajo jurisdicción del Estado en cuestión. Así, en el asunto Hirsi Jamaa y otros contra Italia, este país es condenado por haber incurrido en una violación del art. 3 del CEDH y del art. 4 del Protocolo 4 al haber interceptado en alta mar el navío en el que se encontraban los demandantes procediendo seguidamente a su devolución a Libia, exponiéndolos así a tratos prohibidos por el Convenio ${ }^{26}$.

En este caso, el Tribunal es llamado a pronunciarse por primera vez sobre la aplicabilidad del art. 4 del Protocolo 4 a los casos de expulsiones de extranjeros a un tercer país llevadas a cabo fuera del territorio nacional, sentando así un importante precedente en materia de aplicación extraterritorial del citado instrumento:

Por lo tanto, si el artículo 4 del Protocolo Núm. 4 fuera aplicable solamente a las expulsiones colectivas del territorio nacional de los Estados parte al Convenio, una parte importante de las tendencias migratorias contemporáneas quedarían fuera de su ámbito de aplicación, a pesar de que el tipo de comportamiento que esta disposición busca evitar puede tener lugar fuera del territorio nacional y en particular, como ocurre en el presente caso, en alta $\operatorname{mar}^{27}$.

25 Véase, entre otros, el asunto Čonka c. Bélgica, no.51564/99, ECHR 2002.

26 Hirsi Jamaa y otros c. Italia [GC], no. 27765/09, párr. 137, ECHR 2012.

27 Ibid., párr. 177. 
El Tribunal, que en este asunto adopta una interpretación teleológica de la disposición objeto de examen, introduce el concepto del ejercicio de la jurisdicción extraterritorial como justificación de la aplicabilidad del Convenio:

[...] el Tribunal considera que las expulsiones de extranjeros llevadas a cabo en el marco de intercepciones en alta mar por parte de las autoridades de un Estado que ejerza su competencia soberana, y que tengan como efecto el impedir a los migrantes llegar a las fronteras de este Estado o incluso empujarlos hacia otro Estado, constituyen un ejercicio de jurisdicción en el sentido del artículo 1 del Convenio que implica la responsabilidad del Estado en cuestión en virtud del artículo 4 del Protocolo Núm. $4^{28}$.

Dos años más tarde, en el 2014, esta postura es ratificada en el asunto Sharifi y otros contra Italia y Grecia. En este caso, los demandantes, cuatro nacionales afganos que se encontraban en Grecia, se embarcaron clandestinamente en barcos italianos que se dirigían al puerto de Ancona. Tras su llegada, fueron interceptados por la policía de frontera y devueltos inmediatamente a Grecia. A efectos del presente análisis, la decisión del Tribunal de no entrar a examinar si los demandantes habían llegado o no a Italia cuando fueron expulsados, por su irrelevancia a efectos de la aplicabilidad del art. 4 del Protocolo 4, constituye una ulterior confirmación del alcance extraterritorial de la referida disposición ${ }^{29}$.

Por otro lado, en cuanto al concepto de grupo, a efectos de la identificación de una expulsión colectiva, es importante señalar que, precisamente en la sentencia objeto de estudio, el Tribunal ha afirmado que: «El grupo no tiene que comprender un mínimo de individuos por debajo del cual se pondría en duda el carácter colectivo de la expulsión» ${ }^{30}$. Por consiguiente, el criterio aplicable es de naturaleza cualitativa, en tanto que lo determinante es que en esta clase de expulsiones no se garantiza la posibilidad de realizar alegaciones personales, ni existe la constancia de quién es la persona sujeta a la expulsión, incluso si esa persona está necesitada de una especial protección (Martínez Escamilla, 2016: 91). Además, el hecho de que se dicten resoluciones similares respecto a varias personas no implica necesariamente una expulsión colectiva, siempre y cuando se le haya dado la oportunidad de presentar argumentos contra su expulsión a cada una de las personas afectadas, de manera individual ${ }^{31}$. La medida de expulsión frente a la cual la persona migrante debe

\footnotetext{
Ibid., párr. 180.

29 Sharifi y otros c. Italia y Grecia, n.16643/09, párr. 210-2013, ECHR 2014.

30 N.D. y N.T c. España [GC], nos. 8675/15 y 8697/15, párr. 167, ECHR 2020.

31 Sultani c. Francia, no. 45223/05, párr. 81, ECHR 2007.
} 
poder argumentar debe dictarse por la autoridad competente, entendiendo por tal aquella con capacidad de valorar en su totalidad la argumentación ofrecida contra la expulsión, entrenada adecuadamente en los estándares de derecho nacional e internacional, y estando en condiciones de corroborar los elementos relevantes en caso necesario (Bollo Arocena, 2016: 63). El efectivo cumplimiento de este último requisito constituye, como se verá en el siguiente apartado, una de las cuestiones claves a la hora de determinar la concurrencia de una violación del principio de non-refoulement, considerado por el derecho internacional una norma imperativa o de ius cogens (Pérez González, 2014: 205).

\section{EL CAMBIO DE RUMBO DE LA GRAN SALA: UN ANÁLISIS CRÍTICO}

Seis son los casos en los que, a fecha de hoy, el Tribunal ha constatado la existencia de una violación de la prohibición de expulsión colectiva ${ }^{32}$. En el epígrafe anterior se ha aludido a algunas de las coincidencias y diferencias identificadas entre los mismos. Si bien es cierto que, por un lado, el presente pronunciamiento representa un punto de inflexión en la jurisprudencia del TEDH en materia migratoria, autores como Sánchez Legido evidencian que los indicios que apuntaban a un posible cambio de tendencia en la aproximación del Tribunal Europeo de Derechos Humanos a la prohibición de las expulsiones colectivas y al fenómeno migratorio en general no habían dejado de acumularse (Sánchez Legido, 2020: 236).

En el presente apartado se examinarán en profundidad los argumentos jurídicos esgrimidos por la Gran Sala del TEDH para justificar, en el caso objeto de estudio, la ausencia de violación del derecho a no ser sometido a expulsiones colectivas recogido en el art. 4 del Protocolo 4.

En concreto, se abordarán en detalle los dos aspectos principales del argumento que fundamenta una sentencia sin precedentes en la jurisprudencia del Tribunal: la conducta culpable del demandante como inhibidora de la prohibición de expulsión colectiva y el requisito de la ausencia de razones de peso imputables al Estado demandado para hacer uso del procedimiento legal de entrada. Por último, en el subapartado de «otras cuestiones relevantes»

32 Čonka c. Bélgica, no.51564/99, ECHR 2002; Georgia c. Rusia (I) [GC], no. 13255/07, ECHR 2009; Shioshvili y otros c. Russia, no. 19356/07, ECHR 2007; Berdzenishvili y otros c. Russia, no. 14594/07, ECHR 2019; Hirsi Jamaa y otros c. Italia [GC], no. 27765/09, ECHR 2012 y Sharifi y otros c. Italia y Grecia, n.16643/09, ECHR 2014. 
se hará alusión a algunos de los desarrollos jurídicos más controvertidos de la presente sentencia.

\section{LA CONDUCTA «CULPABLE» DEL DEMANDANTE COMO INHIBIDORA DE LA PROHIBICIÓN DE EXPULSIÓN COLECTIVA}

En el asunto N.D. y N.T c. España, por primera vez en su historia, el TEDH condiciona la protección frente a la expulsión colectiva a la forma de entrada en el territorio de un Estado de la UE. Nunca antes se había planteado la posibilidad de que la entrada no autorizada en el territorio de un Estado pudiera eximir al mismo de la obligación de respetar la prohibición de expulsión colectiva, recogida en el art. 4 del Protocolo 4. A través de la aplicación de la denominada "doctrina de la propia conducta», el Tribunal de Estrasburgo examina si el comportamiento de los demandantes es merecedor de la protección otorgada por el CEDH (Carrera, 2020: 8). Se trata de una resolución que parece ignorar los riesgos que las devoluciones en caliente implican de cara al acceso a la justicia por parte de víctimas de un uso desproporcionado de la fuerza (Carrera, 2020: 10).

Así, la Gran Sala confirma que los hechos son constitutivos de «expulsión» en el sentido del art. 4 del Protocolo 4 en tanto que los demandantes fueron expulsados del territorio español y devueltos a Marruecos, esposados y en contra de su voluntad, por parte de la Guardia Civil. Tras constatar estos hechos, este órgano, revocando la sentencia de la Sección tercera del TEDH, dictamina lo que constituirá una afirmación sin precedentes en el sistema de protección de derechos humanos europeo: que la ausencia de una decisión individual sobre la expulsión de individuo no será constitutiva de una violación del art. 4 si la misma es consecuencia de la conducta culpable del demandante.

Con el fin de justificar esta sorprendente conclusión, la argumentación jurídica que esgrime el Tribunal se basa en la adopción de un doble test: es preciso, por un lado, que el Estado haya facilitado un «acceso real y efectivo a los medios legales de entrada, en particular a los procedimientos fronterizos para quienes llegan hasta la frontera. Dichos medios deberían permitir a todos aquellos que sufren persecución presentar una solicitud de protección, basada en particular en el artículo 3 del Convenio, en condiciones que garanticen un tratamiento compatible con las normas internacionales, incluido el Convenio ${ }^{33}$. En segundo lugar, una vez constatada la existencia de tal acceso, es preciso verificar que la no utilización del mismo por parte del demandante no puede ser objetivamente imputada al Estado. Si no se constata la

33 N.D. y N.T c. España [GC], nos. 8675/15 y 8697/15, párr. 209, ECHR 2020. 
existencia de las referidas razones de peso objetivas que impidan el recurso a los medios legales para solicitar la entrada en un territorio, debe extraerse la conclusión de que el recurso a la expulsión colectiva es consecuencia de la propia conducta del demandante, lo cual justificaría, en última instancia, «que los agentes españoles de frontera no los identificaran individualmente» ${ }^{34}$, o, en otras palabras, el refoulement o expulsión del territorio sin que los demandantes tengan la posibilidad de presentar los argumentos que se oponen a la medida adoptada.

Por lo que respecta a la primera parte de este test, en el presente caso, la Sala, tras examinar las pruebas presentadas, considera probado que los procedimientos legales para entrar en España existían, de facto, como posibilidad real disponible a los demandantes, que, se deduce, decidieron libremente no hacer uso de ellos:

A este respecto, el Tribunal indica que la legislación española ofrecía a los demandantes varias posibilidades para solicitar la admisión en el territorio nacional, ya fuera mediante la solicitud de un visado (véase el párrafo 115 supra) o mediante la solicitud de protección internacional, en particular en el puesto fronterizo de Beni Enzar, pero también en las representaciones diplomáticas y consulares de España en sus países de origen o tránsito, o incluso en Marruecos (véanse los artículos 21 y 38 de la Ley 12/2009, citados en el párrafo 34 supra, y los artículos 4, 16 y 29.4 del Real Decreto 203/1995, citados en el párrafo 35 supra). La disponibilidad y acceso real de dichas vías legales en el presente asunto se examinaron en detalle en las actuaciones ante la Gran Sala, incluso en la vista ${ }^{35}$.

El Tribunal, sin embargo, elude la cuestión central al no entrar a definir lo que constituye un acceso "real y efectivo» a pesar de contar con una sólida jurisprudencia en relación al art. 6, en la que estas nociones, entre otras cosas, exigen la concurrencia de una "oportunidad realista" de acceder a los medios legales "en un modo concreto y efectivo" y que tenga una «base legal clara» que haya sido utilizada en el pasado con éxito (Hakiki, 2020). Además, según algunos autores, la introducción de la primera parte de este test implica que a partir de ahora el art. 4 del Protocolo 4 solo será de aplicación si no ha habido alternativa a la entrada irregular, lo cual es difícilmente verificable si se tiene en cuenta que a la persona víctima de una expulsión colectiva no se le ofrece la posibilidad de explicarse (Pichl y Schmalz, 2020).

Por consiguiente, verificada la concurrencia del primero de los dos requisitos del test, que en última instancia permitirá establecer si ha habido o no

34 Ibid., párr. 211.

35 Ibid., párr. 212. 
violación del art. 4, es preciso abordar el peligroso nexo que la Gran Sala establece entre la entrada en un territorio sin hacer uso de los procedimientos formales existentes a tal efecto y la pérdida del derecho a no ser objeto de una expulsión colectiva reconocido en el art. 4 del Protocolo 4. Afirma el Tribunal que «la propia conducta del demandante es un factor relevante para evaluar la protección que se debe otorgar en virtud del artículo 4 del Protocolo $\mathrm{n}^{\mathrm{0}}{ }^{4} \aleph^{36}$.

En el mismo sentido, en el párrafo 231, la Gran Sala sostiene que:

En consecuencia, de conformidad con su jurisprudencia reiterada, el Tribunal considera que la ausencia de resoluciones individuales de expulsión puede deberse al hecho de que los demandantes, si efectivamente deseaban hacer valer sus derechos en virtud del Convenio, no hicieron uso de los procedimientos formales de entrada existentes a tal efecto, lo que por tanto fue consecuencia de su propia conducta (véanse las referencias en el párrafo 200 supra). Por consiguiente, no ha habido vulneración alguna del artículo 4 del Protocolo no. $4^{37}$.

Además, el Tribunal parece calificar como agravada la conducta «inhibidora» del derecho a no ser objeto de expulsión colectiva analizada en la presente sentencia al aludir al "gran número de personas» que participaron y «se aprovecharon" precisamente de esto, utilizando "la fuerza» y creando una «situación claramente perturbadora, difícil de controlar y que pone en peligro la seguridad pública» ${ }^{38}$. Sin perjuicio de la sanción que estas conductas llevan aparejadas, la doctrina nos recuerda que los castigos colectivos que renuncian a indagar en la responsabilidad individual de los implicados difícilmente encajan con las exigencias derivadas de los arts. 6 y 7 del Convenio (Sánchez Legido, 2020: 252).

\section{EL REQUISITO DE LA AUSENCIA DE RAZONES DE PESO IMPUTABLES AL ESTADO DEMANDADO PARA HACER USO DEL PROCEDIMIENTO LEGAL DE ENTRADA}

Se ha adelantado ya que la segunda parte del test que elabora el Tribunal para determinar si la conducta de los demandantes puede ser calificada que culpable de no haber entrado en el territorio a través de los procedimientos legales disponibles al efecto requiere demostrar que los demandantes no tenían razones de peso imputables al Estado para no valerse de los procedimientos legales de entrada.

\footnotetext{
36 Ibid., párr. 200.

37 Ibid., párr. 231.

38 Ibid., párr. 201.
} 
A priori, este requisito pone de manifiesto una importante contradicción en la argumentación jurídica de la Gran Sala. Al sostener que, si las solicitudes de protección no se presentan en los puestos fronterizos, los Estados "pueden denegar la entrada en su territorio a los extranjeros, incluidos los posibles solicitantes de asilo", el Tribunal de Estrasburgo cuestiona la naturaleza absoluta y erga omnes del principio de non-refoulement (Carrera, 2020: 5). El Tribunal afirma que el Estado puede incumplir su prohibición de aplicar medidas de expulsión colectiva si la decisión de «optar» por la vía ilegal puede ser imputada exclusivamente al demandante en el entendido de que el Estado garantiza un acceso real y efectivo a los medios legales para solicitar la entrada.

Así pues, en aplicación del doble test que propone el Tribunal para constatar la existencia de una violación, es preciso que los demandantes no tuvieran motivos de peso para no valerse de estos procedimientos. Otra cuestión relevante que surge en este asunto es la de la carga de la prueba ya que, al tratarse de un indicador negativo ("la no concurrencia de motivos de peso»), en principio parece recaer sobre el demandante, que tiene que probar que concurrían las razones de peso objetivas que le impidieron acceder a los procedimientos de entrada legales. En el párrafo 211, el Tribunal afirma literalmente que

este Tribunal debe determinar si las opciones que [...] estaban a disposición de los demandantes para entrar legalmente en España [...] y, en caso afirmativo, si los demandantes podían acceder a ellas de forma real y efectiva. [...] sólo la ausencia de razones de peso (como se describe en el párrafo 201) que impidieran el uso de dichos procedimientos podría conducir a la conclusión de que ello fue consecuencia de la propia conducta de los demandantes ${ }^{39}$.

Al referirse a los términos del párrafo 201, el Tribunal alude a un importantísimo matiz que resulta clave para que la presente sentencia aboque a los demandantes a un callejón sin salida en el cual, de facto, no es posible obtener una tutela de los derechos fundamentales. Al especificar que la razón de peso que impida al demandante acceder a los medios legales de solicitud de entrada en el territorio debe ser necesariamente imputable al Estado («de los que el Estado demandado sea responsable» ${ }^{40}$ ), el Tribunal rechaza entrar a conocer de los obstáculos reales y objetivos al acceso a medidas legales de entrada en España no imputables a este Estado, pese a que, tal y como denuncia la doctrina, son numerosas y en algunos casos bastante autorizadas las fuentes

$\begin{array}{ll}39 & I d . \\ 40 & I d .\end{array}$ 
que denuncian que el acceso a los puestos fronterizos de Ceuta y Melilla es imposible para los inmigrantes subsaharianos como consecuencia de la acción represiva de los efectivos de la Fuerza Auxiliar Marroquí (Sánchez Legido, 2020: 256).

Entre las muchas consecuencias de esta decisión, es preciso destacar que ello invalida las alegaciones presentadas por ACNUR, parte en el procedimiento, que sostiene que "hasta noviembre de 2014, no era posible solicitar el asilo en los puestos fronterizos de Melilla y que no había ningún mecanismo para identificar a las personas que necesitarán protección internacional» ${ }^{41}$. Aún más graves son las afirmaciones presentadas por el Comisario de Derechos Humanos, que, tras recordar la creación de una oficina encargada de las cuestiones de asilo en Beni-Enzar, uno de los puntos de paso entre Melilla y Marruecos, apuntó que «aparte de las personas que huían del conflicto sirio, esta posibilidad ha quedado fuera del alcance de las personas originarias del África subsahariana $»^{42}$. Al optar por no darle peso a las alegaciones de las terceras partes en el proceso, el Tribunal se aparta de su enfoque tradicional en virtud del cual, ante versiones contradictorias de los hechos, otorgaba una especial relevancia a los informes de organismos independientes ${ }^{43}$.

De lo anterior se desprende que las razones de peso para no recurrir a los procedimientos legales de entrada disponibles solo son relevantes si son imputables al Estado demandado. Si, de facto, por motivos imputable a un tercer Estado, como en el presente asunto parece ser el caso de Marruecos, los demandantes no pueden acceder efectivamente a los mecanismos legales para solicitar la entrada en el territorio de un Estado, el Tribunal no los toma en consideración ${ }^{44}$.

$41 \quad$ Ibid., párr. 87.

42 Ibid., párr. 86. Para una visión crítica que cuestiona la validez de las pruebas presentadas y evaluadas por la Gran Sala en este caso, véase el informe presentado como resultado de la investigación realizada por Forensic Architecture y la ONG European Centre for Constitutional and Human Rights (ECCHR). Disponible aquí: https://bit. ly/32JxNVw. Véase también el análisis cruzado de las estadísticas de visados emitidos en Melilla y los datos de Eurostat sobre las denegaciones de entrada en España que realiza Carrera (2020: 10-17).

43 Hirsi Jamaa y otros c. Italia [GC], no. 27765/09, párr. 18, ECHR 2012; M.S.S. c. Bélgica y Grecia [GC], no. 30696/09, párr. 227, ECHR 2011.

44 Véase, en este sentido, la denuncia efectuada por el periódico elDiario.es. Gabriela Sánchez y Raúl Sánchez (2017). La ONU y los datos de Interior desmontan el último discurso de Zoido para defender las devoluciones en caliente, elDiario.es, 13-10-2017. Disponible en: https://bit.ly/35sFJwc. 
Más allá de las cuestiones de coherencia con el CEDH y con la propia jurisprudencia del Tribunal que inevitablemente plantea la anterior afirmación, al introducir la existencia de tal acceso como uno de los dos requisitos claves para establecer la concurrencia de una efectiva violación del art. 4 del Protocolo 4, la Gran Sala asume una tarea de difícil realización. Así, la duda que plantea la jueza Koskelo en su voto parcialmente discrepante, cuando se pregunta si el Tribunal «estará en condiciones de garantizar realmente una "protección eficaz» con respecto al "acceso real y efectivo a los medios de entrada legal» es del todo pertinente, sobre todo teniendo en cuenta que «la supervisión del Tribunal sólo se llevará a cabo con carácter retroactivo y con considerables retrasos» ${ }^{45}$.

\section{OTRAS CUESTIONES RELEVANTES}

$\mathrm{Al}$ referirse a la falta de alusión a las circunstancias que harían a los demandantes beneficiarios del asilo, el Tribunal se excede en sus competencias. Es difícil no coincidir en este punto, aunque por razones distintas, con el voto parcialmente discrepante de la jueza Koskelo, por lo demás altamente cuestionable, cuando afirma que "garantizar el acceso a los procedimientos de asilo a los extranjeros que deseen entrar en la jurisdicción de un Estado Parte no es una cuestión que entre en el ámbito del Convenio y, por consiguiente, no es una cuestión que deba analizar el Tribunal». La argumentación que sostiene esta tesis se basa, según la magistrada finlandesa, en que el

grado en que el Convenio regula las cuestiones relativas al asilo y la protección internacional se limita a la obligación de no devolución, tal y como se contempla en los artículos 2 o 3, es decir, el deber de los Estados contratantes de no expulsar o entregar a nadie que se encuentre dentro de su jurisdicción a otra jurisdicción cuando esa persona se viese sometida a un riesgo real de recibir un trato prohibido en virtud de dichas disposiciones.

Si por un lado es cierto que al examinar la presunta violación del art. 4 del Protocolo 4 el Tribunal no tendría que haber entrado en disquisiciones sobre si se cumplían los requisitos para el asilo, ello no altera el precedente establecido por el Tribunal en virtud del cual el Proyecto de Artículos sobre la Expulsión de Extranjeros de la Comisión de Derecho Internacional es aplicable a todos los extranjeros en su territorio, independientemente de su

45 N.D. y N.T c. España [GC], nos. 8675/15 y 8697/15, voto parcialmente discrepante de la jueza Koskelo párr. 42, ECHR 2020. 
calificación como migrantes o refugiados ${ }^{46}$. Así lo confirmó en el presente caso, en el que reconoció que la protección otorgada por el art. 4 del Protocolo 4 y por el artículo 3 del CEDH es aplicable a cualquier extranjero ${ }^{47}$.

Sin perjuicio de lo anterior, la aplicación generalizada del principio de no devolución en el derecho migratorio y de asilo choca frontalmente con la sentencia objeto de estudio, que, en última instancia, avala las devoluciones en caliente, con el resultado de generar dos criterios jurídicos contradictorios sobre los derechos de las personas migrantes.

En el presente caso, los demandantes también alegan la violación del art. 13 del Convenio, que tutela el derecho a un recurso efectivo ante una instancia nacional, cuando un derecho o libertad reconocido en el Convenio haya sido violado «incluso cuando la violación haya sido cometida por personas que actúen en el ejercicio de sus funciones oficiales ${ }^{48}$. Con el fin de profundizar en este aspecto, conviene traer a colación la jurisprudencia sentada por el TJUE en el asunto Boudjlida en 2014, caso al que se refiere el Tribunal en la sentencia dictada en primera instancia por la Sección tercera. Al pronunciarse sobre la tutela judicial efectiva, el Tribunal se refiere al derecho a ser oído como un derecho que garantiza «cualquier persona la posibilidad de expresar de manera adecuada y efectiva su punto de vista durante el procedimiento administrativo y antes de que se adopte cualquier decisión que pueda afectar desfavorablemente a sus intereses» ${ }^{49}$.

En este punto, como en muchos de los analizados en el presente pronunciamiento, la Gran Sala se aparta de su jurisprudencia consolidada con la consecuencia de inhibir al Estado español de su responsabilidad de poner a disposición un recurso judicial contra una expulsión que potencialmente podría ser constitutiva de una violación de un derecho fundamental, con el siguiente argumento: «En la medida en que el Tribunal ha considerado que la falta de un procedimiento individualizado para su expulsión fue consecuencia de la propia conducta de los demandantes al intentar entrar sin autorización en Melilla (véase el párrafo 231 supra), no puede considerar responsable al Estado demandado por no haber puesto a su disposición un recurso judicial contra dicha expulsión ${ }^{50}$.

46 Khlaifia y otros c. Italia, no. 16483/12, párr. 243, ECHR 2016; Hirsi Jamaa y otros c. Italia [GC], no. 27765/09, párr. 174, ECHR 2012.

47 N.D. y N.T c. España [GC], nos. 8675/15 y 8697/15, párr. 187, ECHR 2020.

48 Art. 13 CEDH.

49 Sentencia del Tribunal de Justicia de 11 de diciembre de 2014, Boudjlida, C-249/13, EU:C:2014:2431, apdo. 36.

50 N.D. y N.T c. España [GC], nos. 8675/15 y 8697/15, párr. 242, ECHR 2020. 


\section{CONCLUSIÓN}

Estamos ante una sentencia que cambia completamente el rumbo de la jurisprudencia del TEDH en relación al art. 4 del Protocolo 4. La transformación que se deriva del reconocimiento de las expulsiones sumarias como una respuesta admisible frente a los intentos de entrada irregular en territorio europeo ha llegado a sorprender incluso al Parlamento Europeo ${ }^{51}$, ha desmentido las previsiones de la doctrina que confiaba en que la fuerza de los argumentos de la Sección tercera garantizase su confirmación por la Gran Sala (Gortázar, 2017).

Sin embargo, es curioso notar cómo, tras este pronunciamiento, el Tribunal parece haber vuelto sobre sus pasos: el 24 de marzo de 2020, apenas un mes después de la sentencia dictada en el presente caso, en el asunto $A s a d y$ y otros contra Eslovaquia, el TEDH reintroduce el requisito de la «auténtica y efectiva oportunidad de presentar argumentos en contra de su expulsión " ${ }^{52}$ por parte del Estado en el que se encuentran los demandantes, tras haber atravesado de manera irregular la frontera entre Ucrania y Eslovaquia, antes de ser devueltos a Ucrania. Resulta incluso llamativa la alusión a la sentencia del caso N.D. y N.T contra España para ilustrar precisamente un ejemplo de una situación en la que a los demandantes, tras atravesar la frontera de manera no autorizada, se les niega el acceso a un procedimiento legal de entrada: «The Court notes that, although the applicants had crossed the Slovak border in an unauthorised manner, they were intercepted in the territory of Slovakia and the State provided them access to means of legal entry through the appropriate border procedure (see, conversely, N.D. and N.T. v. Spain, cited above) ${ }^{53}$.

Estamos, pues, ante un pronunciamiento que condiciona la aplicabilidad de la prohibición de expulsión colectiva a la conducta del demandante, utilizando para ello un test cuya dudosa eficacia ha sido evidenciada en este comentario, que representa un precedente potencialmente restrictivo, si no lesivo, del contenido y alcance de los derechos humanos protegidos por el $\mathrm{CEDH}$. El mismo ha sido definido por el CEAR como «uno de los mayores

51 Véase el borrador del Informe de implementación de la directiva del retorno presentado en junio de 2020 por el Servicio de Investigación del Parlamento Europeo (EPRS, por sus siglas en inglés), p. 158: «Starkly juxtaposed against the Court's jurisprudence on Article 4 Protocol 4 sits the recent Grand Chamber decision in N.D. which attributed the applicants' own behaviour for them not receiving individual removal decisions because they did not resort to official entry procedures to enter Spain to claim their rights under the ECHR». Disponible en: https://bit.ly/3plQwAd.

Asady y otros c. Eslovaquia, no. 24917/15, párr. 65 y párr. 71 ECHR 2020.

Ibid., párr. 62. 
retrocesos en materia de derechos humanos que hace dudar de la propia universalidad de los mismos ${ }^{54}$. Llegados a este punto, quizás convenga aludir a las razones que llevan a Sánchez Legido a considerar posible una rectificación parcial por parte de la Gran Sala. El autor sostiene que al rechazar los argumentos vinculados a su jurisdicción y al concepto de expulsión que habían avanzado los Gobiernos participantes en el procedimiento, el Tribunal se reserva la posibilidad de afinar en el futuro el aval otorgado a este tipo de prácticas (Sánchez Legido, 2020: 257).

Este pronunciamiento no puede entenderse sin aludir a las presiones a las que se ha visto sometido el Tribunal de Estrasburgo por parte de los Gobiernos nacionales en los casos relacionados con las políticas migratorias y de asilo (Riemer, 2019), que se han incluso intentado positivizar ${ }^{55}$, y que, en última instancia, se han visto reflejadas en el Nuevo Pacto Europeo de Migración y Asilo presentado hace tan solo unas semanas analizado en la primera parte de este trabajo.

Con dos casos actualmente pendientes contra España por presunta violación del art. 4 del Protocolo 4 en circunstancias similares ${ }^{56}$, a este Tribunal se le brinda una nueva oportunidad de aclarar cuál será su legado en este ámbito, recordando que, en última instancia, sus pronunciamientos tienen como objetivo salvaguardar y desarrollar las reglas recogidas en la Convención ${ }^{57}$.

\section{Bibliografía}

Bollo Arocena, M. D. (2016). Expulsión de extranjeros, derecho internacional y derecho europeo. Pamplona: Thomson Reuters Aranzadi.

54 Comisión Española de Ayuda al Refugiado (2020), Análisis de la sentencia N.D. y N.T contra España de 13 de febrero de 2020, p. 8

55 Véase la disposición 26 de la primera versión del borrador de la Declaración de Copenhague (5 de febrero de 2018), negociada en abril de 2018 por iniciativa de la Presidencia danesa del Consejo de Europa, que tenía como objetivo reexaminar el sistema de protección de los derechos humanos establecido por la CEDH: «When examining cases related to asylum and immigration, the Court should assess and take full account of the effectiveness of domestic procedures and, where these procedures are seen to operate fairly and with respect for human rights, avoid intervening except in the most exceptional circumstances». Disponible aquí: https://bit.ly/2GWyHpN.

56 Mamadou Alpha Balde y Raoul Abel c. España, [demanda presentada el 9 de marzo de 2017], no. 20351/17], ECHR y Albert Julio Doumbe Nnabuchi contra España, [demanda presentada el 13 de abril de 2015], no. 19420/15, ECHR.

57 Konstantin Markin c. Rusia [GC], párr. 89, no. 30078/06, ECHR 2012. 
Carrera, S. (2020). The Strasbourg Court Judgement N.D. and N.T. v Spain A Carte Blanche to Push Backs at EU External Borders? EUI Working Paper RSCAS 2020/21. European University Institute. Disponible en: https://doi. org/10.2139/ssrn.3634515.

Castilla, K. (2017). N.D y N.T contra España: más que las devoluciones en caliente, menos que un recurso con las máximas garantías. Institut de Drets Humans de Catalunya [blog], 18-12-2017. Disponible en: https://bit.ly/3kdLJgX.

Cobos Romero, J.C. (2017). Análisis de la sentencia del Tribunal Europeo de Derechos Humanos N.D. y N.T. contra España del 3 de octubre de 2017 [Trabajo de fin de máster]. Universidad de Deusto. Disponible en: https://bit.ly/37mtgLA.

De Lucas, J. (2015). Mediterráneo: El naufragio de Europa. Valencia: Tirant Humanidades.

Gortázar, C. (2017). A cold shower for Spain-hot returns from Melilla to Morocco: N.D. and N.T. v Spain ECtHR. Eumigrationlawblog [blog], 3-10-2017. Disponible en: https://bit.ly/3o81zMG.

Hakiki, H. (2020). N.D. and N.T. v. Spain: defining Strasbourg's position on push backs at land borders? Strasbourgobservers [blog], 26-3-2020. Disponible en: https://bit.ly/3dILPen.

Hérnandez Bologna, A.C. (2020). Expulsiones colectivas. Análisis de la sentencia del TEDH en el caso N.D. y N.T contra España [Trabajo de fin de máster]. Universidad Carlos III de Madrid.

Martínez Escamillas, M. (2016). Devoluciones en caliente. Un análisis jurídico. En J. L. Villena Higueras (coord.). Derechos humanos y justicia universal en la frontera sur (pp. 77-96). Granada: Universidad de Granada.

Pérez González, C. (2014). Límites a la lucha contra la inmigración irregular por vía marítima impuestos por el derecho internacional de los derechos humanos. En L. L. Hierro (coord.). Autonomía individual frente a autonomía colectiva. Derechos en conflicto (pp. 193-218). Madrid: Marcial Pons.

Pijnenburg, A. (2017). Is N.D. and N.T. v. Spain the new Hiris? Ejiltalk [blog], 17-10-2017. Disponible en: https://www.ejiltalk.org/is-n-d-and-n-t-v-spainthe-new-hirsi/.

Pichl, M. y Schmalz, D. (2020). "Unlawful» may not mean rightless: The shocking ECtHR Grand Chamber judgment in case N.D. and N.T. Verfassungsblog [blog], 14-2- 2020. Disponible en https://verfassungsblog.de/unlawful-may-notmean-rightless/.

Riemer, L. (2019). The ECtHR as a drowning 'Island of Hope' Its impending reversal of the interpretation of collective expulsion is a warning signal. Verfassungsblog [blog], 19-2-2019. Disponible en: https://bit.ly/3jiWA8a.

Sanchez Legido, A. (2020). The Spanish pushback policy before the Strasbourg court: strengthening the walls of fortress Europe? Revista Española de Derecho Internacional, 72 (2), 235-260.

Solanes Corella, Á. (2017). Contra la normalización de la ilegalidad: la protección judicial de los extranjeros frente a las expulsiones colectivas y las devoluciones 
«en caliente». Cuadernos Electrónicos de Filosofía del Derecho, 36, 195-225. Disponible en: https://doi.org/10.7203/CEFD.36.11269.

Thym, D. (2020). A Restrictionist Revolution? A Counter-Intuitive Reading of the ECtHR's N.D \& N.T. Judgement on "Hot Expulsions". Eumigrationlawblog [blog], 17-2-2020. Disponible en: https://bit.ly/2HiEGVO.

Vacas Fernández, F. (2017). El Derecho Migratorio, Internacional y Europeo, como Limite desde los Derechos Humanos a la Discrecionalidad de los Estados en Materia Migratoria. Valencia: Tirant lo Blanch. 